\title{
Compensation of a Cavitary Bone Defect in Conditions of Implantation of Mesh Structures from Titanium Nickelide
}

\author{
Yuri M. Iryanov, $\mathrm{PhD}, \mathrm{ScD}^{1 *}$; Nikolay A. Kiryanov, $\mathrm{PhD}, \mathrm{ScD}^{2}$ \\ ${ }^{1}$ Russian Ilizarov Scientific Center Restorative Traumatology and Orthopedics, Kurgan, Russia \\ ${ }^{2}$ Izhevsk State Medical Academy, Izhevsk, Russia
}

\begin{abstract}
The purpose of our research was to study reparative osteogenesis for implanting mesh structures of titanium nickelide into a cavitary bone defect.

Methods: The authors modeled cavitary defects of femoral metaphysis experimentally in Wistar rats divided into an experimental and a control group. The study duration was 60 days in total. Scanning electron microscope JSM-840 (JEOL, Japan) equipped with energy dispersive X-ray analyzer (INCA 200, Oxford Instruments) was used.

Results: Under implantation, the defect was filled with cancellous bone the volumetric density of which exceeded control values more than 1.5 -fold $(P<0.001)$. The implant had biocompatibility, osteoconductive and osteoinductive properties, and it stopped inflammatory processes. The membrane protective barrier, which prevented connective tissue sprouting, was formed on the surface of the implant in the defect periosteal zone. The osteointegrative junction was formed and persisted up to the end of the experiment. Reparative osteogenesis was performed by direct intramembranous and apposition type.

Conclusion: The implant of three-dimensional mesh titanium-nickelide structures has marked osteoplastic properties, and it can be successfully used in orthopedic surgery. (International Journal of Biomedicine. 2018;8(4):337-341.)
\end{abstract}

Key Words: reparative osteogenesis $\bullet$ titanium nickelide implant $\bullet$ cavitary bone defect $\bullet$ osteoplastic properties

\section{Introduction}

Connective tissue ingrowth from the periosteal surface is the main obstacle to restitution of large-volume bone defects that are caused by a higher rate of migrating fibroblasts compared to that of osteogenic cells..$^{(1,2)}$ This can inhibit the reparative osteogenesis process completely or partially, as well as be a cause of the defect filling with dense connective tissue of scar type. In order to create optimal conditions for formation of organotypic regenerated bone, the technique of guided reparative osteogenesis was developed using the membrane technology, which prevented connective tissue sprouting. ${ }^{(3,4)}$ For this purpose, we used the membranes of synthetic and natural materials, which, however, are not osteointegrated; they can cause an inflammatory reaction and tissue swelling, in which case a repeat surgical intervention is required. ${ }^{(5,6)}$

*Corresponding author: Prof. Yuri M. Iryanov, PhD, ScD; Laboratory of Morphology, Russian Ilizarov Scientific Center Restorative Traumatology and Orthopedics, Kurgan, the Russian Federation.E-mail: irianov@mail.ru
The membrane barrier over the bone defect that has good contact with the edges of the defect creates a closed space between the "mother" bone and the membrane. The membrane acts as a mechanical protective barrier, preventing the germination of connective tissue into the defect. Only the cells responsible for reparative osteogenesis fall into the defect from the surrounding bone tissue. In this case, there is a process of directed osteogenesis without the influence of other tissues. Numerous studies have been performed to elucidate the main features of directed bone regeneration, ${ }^{(8-11)}$ but a number of issues remain unclear to this day. In particular, it is not clear whether there is a difference in the effect of regeneration from placement of osteoconductive or osteoinductive materials in the closed space between the bone and the membrane. Can individually manufactured membranes be used to achieve the desired shape and volume of bone tissue in the defect? New possibilities have arisen due to medical technologies that produce implants based on nickel and titanium, which are approached to bone tissue by their mechanical characteristics and are biocompatible. ${ }^{(12)}$

The purpose of our research was to study reparative 
osteogenesis for implanting mesh structures of titanium nickelide $(\mathrm{TN})$ into a cavitary bone defect.

\section{Materials and Methods}

\section{Description of the intervention}

Cavitary defects of femoral metaphysis were modeled in adult male Wistar rats in both the experimental and control groups ( $\mathrm{n}=20$ in each group); the defect volume was $0.02 \mathrm{~cm}^{3}$, which accounted for about $40 \%$ of the total metaphysis volume. The volume of the metaphysis was determined by the volume of water displaced by it. The defect was filled with water by using a measuring syringe. All manipulations were carried out in accordance with "European Convention for the Protection of Animals used for Experimental and other Scientific Purposes" and approved by the National Ethics Committee. The implant was introduced into the defects in the animals of the experimental group; no additional manipulations were performed in the control group.

\section{Characteristics of the implant}

The implant had a mass of $0.017 \pm 0.001 \mathrm{~g}$, a volume of $0.02 \pm 0.001 \mathrm{~cm}^{3}$. The implant was a mesh framework made of nickelide-titanium thread (TH-10 brand of $90 \mu \mathrm{m}$ caliber) formed by the type of knitting with cells - through open pores of 100-300 $\mu$ m diameter. ${ }^{(13)}$ The thread was made of composite material comprising a core of nanostructured monolithic TN and a titanium-oxide microporous surface layer of 5-7 $\mu \mathrm{m}$ (Research and Production Enterprise "MITs", Tomsk, Russia; Certificate No POOCRU.AЯ79H18304). The micro relief of the surface layer of the filament was characterized by sharply pronounced roughness and nanostructuredness and the presence of a multitude of interconnected, open-capillary micro pores (Figures 1a, 1b, 1c). The porosity of the implant was $73.6 \pm 3.56 \%$.

\section{Methods of research and registration of outcomes}

The animals were withdrawn from the experiment after 7, 14, 30 and 60 days (five animals were used for each time point). The bone meta-epiphyseal zone was sewn out, fixed in $2 \%$ paraformaldehyde and glutaraldehyde solution and embedded in araldite (without decalcification). The araldite blocks were studied using a scanning electron microscope JSM-840 (JEOL, Japan) equipped with energy dispersive X-ray analyzer (INCA 200, Oxford Instruments), and images (maps) were obtained in the characteristic X-ray emission of calcium atoms. The structures of bone tissue were visualized and the necessary measurements were made. The bulk density of bone tissue was determined (in \%) as the ratio of the area occupied by bone structures in the image to the total area of the map. We then calculated the bone tissue compactness index (ratio of bone structure and non-mineralized components) and concentration of osteotropic macronutrients (calcium, phosphorus, magnesium, sodium and sulfur) in the bone regenerate.

Statistical analysis was performed using StatSoft Statistica v6.0. The mean and standard error of the mean were calculated. The Mann-Whitney (U Test) was used to compare the differences between the two independent groups. A probability value of $P<0.05$ was considered statistically significant.

\section{Results}

The process of bone formation that occurred from periosteum, endosteum, bone marrow and the damaged bone structures of the defect edges was observed in the both groups of animals 7 and 14 days after surgery. In the control group, a non-matured regenerated bone (of connective-tissue type) was formed in the periosteal zone; its collagen fibers grew from periosteum into the central zone of the defect as strip-like bundles.

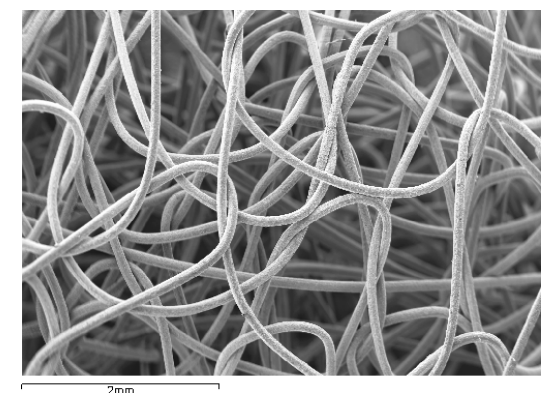

(a)

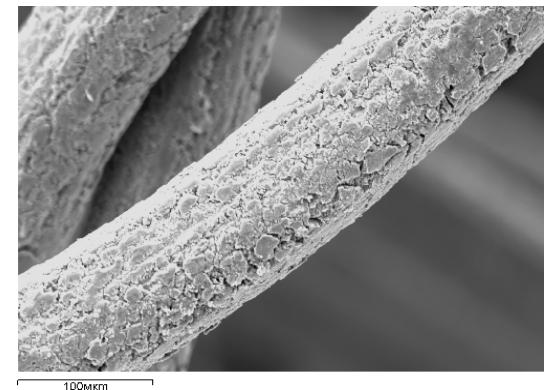

(b)

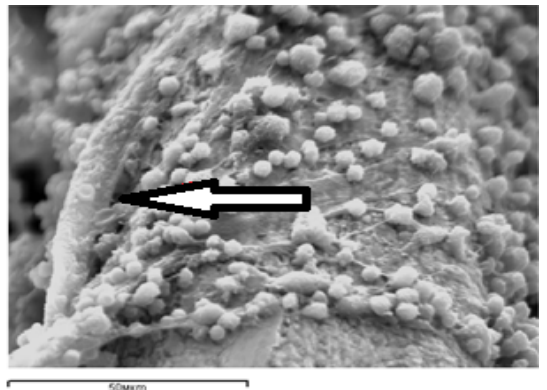

(c)

Fig. 1. A mesh design made of TN implanted into the defect of the metaphysis of the femur: (a) - general view of the implant, (b) - micro relief of the surface layer of the implant filament, (c) - adhesion of slightly differentiated cells and newly formed capillary terminals (arrow) on the surface of the filament 7 days after the operation. Scanning electron microscopy (SEM), magnification: (a) - $\times 13$, (b) $\times 190$, (c) $-\times 475$.

Table 1.

Bone tissue volumetric density in the metaphysis defect in the animals from the control group (Cont) and experimental group (Exp) and in the intact metaphysis of the contralateral limb

\begin{tabular}{|c|c|c|c|c|c|c|c|}
\hline \multirow{2}{*}{ Parameters } & \multicolumn{6}{|c|}{ Period of the experiment, days } & \multirow{2}{*}{$\begin{array}{c}\text { Metaphysis of } \\
\text { contralateral } \\
\text { limb }\end{array}$} \\
\hline & \multicolumn{2}{|c|}{14} & \multicolumn{2}{|c|}{30} & \multicolumn{2}{|c|}{60} & \\
\hline Bone tissue, \% & $\begin{array}{c}\text { Cont } \\
8.443 \pm 0.381\end{array}$ & $\operatorname{Exp}_{12.174 \pm 0.613^{1}}$ & $\begin{array}{c}\text { Cont } \\
13.543 \pm 0.681\end{array}$ & $\operatorname{Exp}_{19.764 \pm 0.962^{1}}$ & $\begin{array}{c}\text { Cont } \\
15.022 \pm 0.744\end{array}$ & $\operatorname{Exp}_{22.984 \pm 1.094^{1}}$ & $25.072 \pm 1.212$ \\
\hline Compactness index & $0.092 \pm 0.005$ & $0.143 \pm 0.012^{3}$ & $0.164 \pm 0.013$ & $0.252 \pm 0.021^{2}$ & $0.181 \pm 0.013$ & $0.310 \pm 0.021^{2}$ & $0.333 \pm 0.024$ \\
\hline
\end{tabular}

1, 2, ${ }^{3}$ Statistical significance of intergroup differences: ${ }^{1} P<0.001,{ }^{2} P<0.01,{ }^{3} P<0.05$ 
The defect was filled with loose connective and granulation tissue, where the foci of lymphocytic and plasmacytic infiltration and fibrin clots were located. The islets of reticulofibrous bone tissue, represented as a fine-cellular network of interwoven bone-osteoid trabeculae, were formed near the outer edges of the defect in the periosteum, as well as in the endosteum. Located near the defect's inner edges were randomly arranged fragments of the damaged bone structures, as well as separate unrelated foci of newly formed bone tissue as short bone-osteoid trabeculae lining the inner surface of the defect. In the control group, the bone tissue volumetric density in the defect and the compactness index of the regenerated bone amounted to about $30 \%(P<0.001)$ of the intact metaphysis values 14 days after surgery (Table 1 ).

In the experimental group, a thin membrane-like cover of connective tissue was observed around the implant threads and cells in the defect periosteal zone 7 and 14 days after surgery (Figure 2a). The cover formation began on the surface of the thread in the woven places and spread from the periphery of the cells to their center. The cover had a layered structure. The inner layer consisted of dense formalized connective tissue. Collagen fibers were collected into dense, circularly oriented, lace-like bundles, and they braided the implant threads in the form of a sleeve; they were firmly fixed to microporous surface of the threads, grew into the gaps between them and provided the fixation of the implant threads both between each other and in the bone defect (Figure 2b).

Areas of active appositional bone formation were observed below the connective-tissue cover in the endosteal and central zone of the defect and at its edges around the implant structures, as well as on their surface. A layer of reticulofibrous bone tissue of 300-400 $\mu \mathrm{m}$ thickness emerged on the surface of the implant thread directly forming an osteointegration connection (Figure 3a).

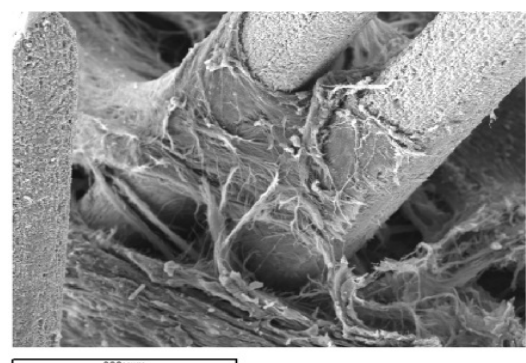

(a)

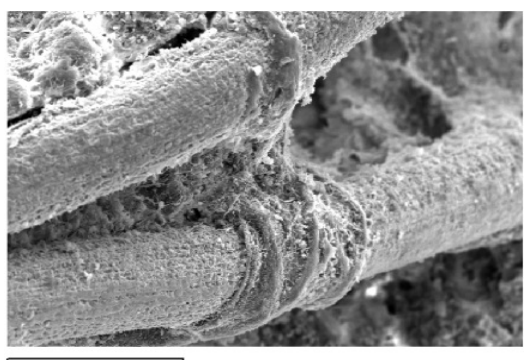

(b)
The implant threads in the osteointegration areas were coated with mineralizing bone matrix. Newly formed trabeculae grew into the implant's fine-cellular structure (Figures $3 \mathrm{~b}$ and $3 \mathrm{c}$ ). The results of quantitative studies (Table 1) evidenced significant activation of reparative osteogenesis, as well as of an increased degree of maturity of newly formed bone tissue in the regenerated bones of the animals in the experimental group compared to those in the control group. The bulk density of bone tissue in the defect in the animals of the experimental group was greater by $44.19 \%$, and the compactness index by $55.56 \%$ compared to the values in the control group $(P<0.001)$.

In the control group, the defect was filled with regenerated bone 30-60 days after surgery, where little-mineralized, dense, unformed, connective tissue growing into the defect from the periosteal surface prevailed. The initial stages revealed periosteal-intermediary uniting and forming a cortex with structure resembling cancellous bone (Figures $4 \mathrm{a}$ and $4 \mathrm{~b}$ ).

The operated metaphyseal zone acquired a marked conical shape. Little-calcified dense connective tissue prevailed in the periosteal zone of the regenerated bone. The fine-cellular bone structures of the periosteal regenerated bone fused with endostea newly formed trabeculae, and arcuate grew into the central zone of the defect and formed a thin crescent layer of newly formed cortical bone. Osteogenesis foci were observed in the central and marginal zones of the defect, where osteoid areas were revealed, as well as fragments of newly formed, little-mineralized, reticulofibrous bone trabeculae isolated from each other by wide interlayers of loose connective tissue with the cavities filled with lymphocytic and macrophage elements. The volumetric density of bone tissue in the defect, the index of compactness of the regenerated bone, and the content of calcium and phosphorus amounted to $50-60 \%$ of the intact metaphysis values $(P<0.001)($ Table 1,2$)$.

Fig. 2. Connective-tissue cover on the implant surface in the defect 7 (a) and 14 (b, c) days after surgery. SEM, magnification $\times 160$.

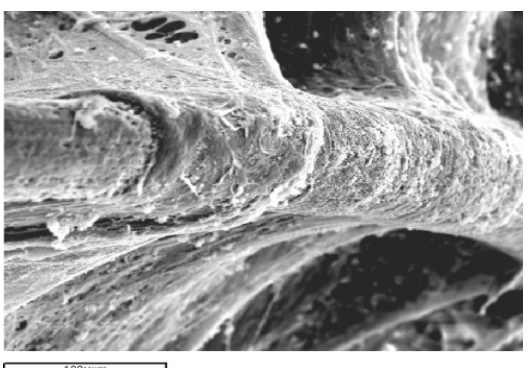

(c) (a)

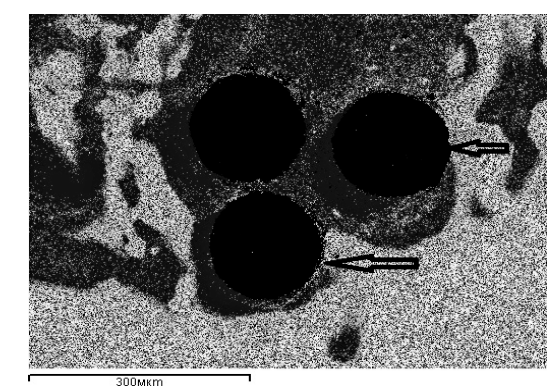

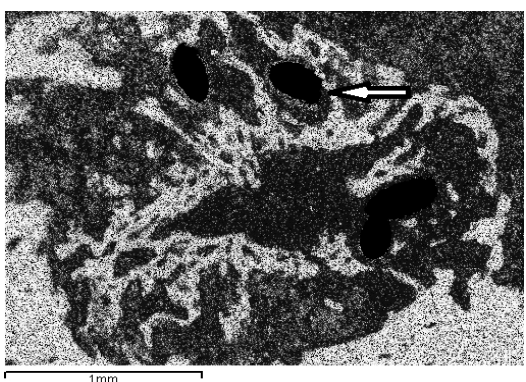

(b)

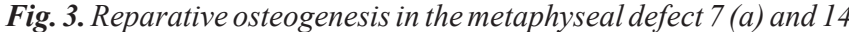
removed with $6 \%$ sodium hypochlorite solution), magnification: $a-\times 100, b-\times 25, c-\times 70$

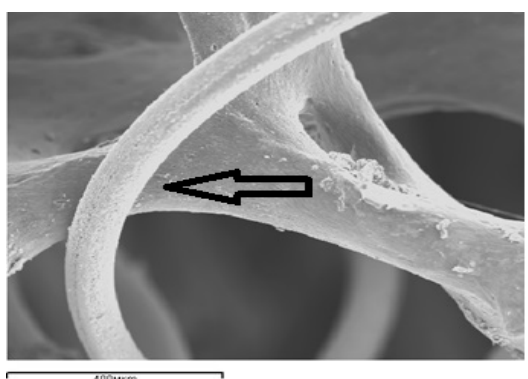

(c) 


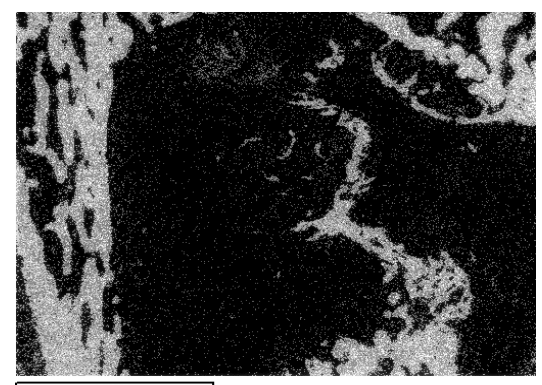

(a)

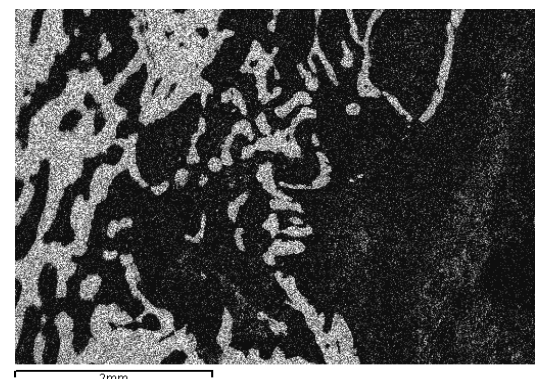

(d)

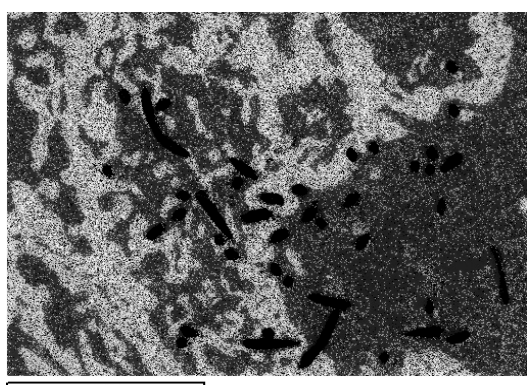

(b)

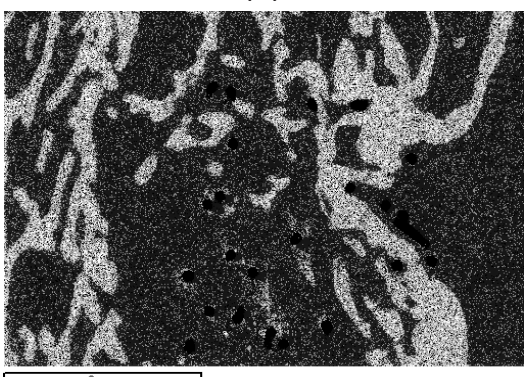

(e)

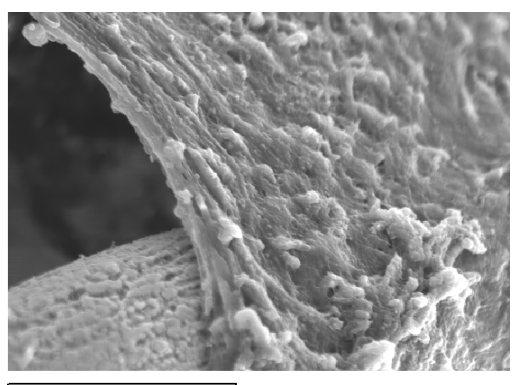

(c)

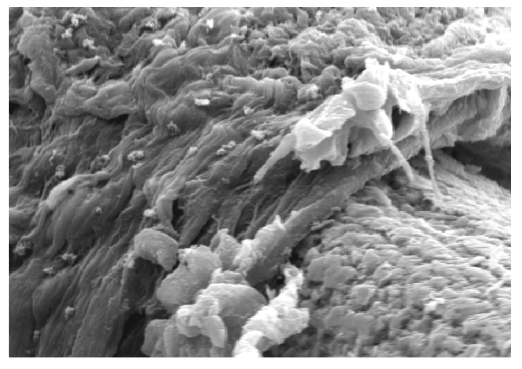

(f)

Fig. 4. Reparative bone formation in the defect of femoral metaphysis in the control ( $a, d)$ and experimental ( $b, c, e, f)$ groups of animals; a, $b, c$ - 30 days after operation; $d, t, f-60$ days after operation; $a, b, d$, e-maps of $x$-ray electron probe microanalysis, mage in characteristic $X$-ray emission of calcium atoms, magnification $\times 20 ; c, f-$ scanning electron microscopy, magnification: $c-\times 670, f-\times 800$.

In the experimental group, the area of bone defect was filled with regenerated bone, where cancellous bone prevailed 30-60 days after surgery (Figures $4 \mathrm{~b}$ and $4 \mathrm{e}$ ). A new area of cortical layer was formed, represented as compact bone of lamellar structure. Bundles of collagen fibers of the protective cover dense connective tissue were located on the periosteal surface of the defect around the implant, which formed an interweaving of the village fence type (Figures $4 \mathrm{c}$ and $4 \mathrm{f}$ ). The implant threads were surrounded by osteoid or they were completely overgrown by newly formed bone tissue, thereby forming a composite - compact bone reinforced by TN. Bone tissue volumetric density, index of compactness, and degree of mineralization of the regenerated bone were somewhat less compared to the intact metaphysis values, but these differences were not statistically significant by the end of the experiment, and, at the same time, they exceeded the values in the control group by more than 1.5 -fold $(P<0.001)$ (Tables 1 and 2$)$.

\section{Table 2.}

Content of osteotropic chemical elements in the regenerated bone of the control group (Cont) and experimental group (Exp) of animals 60 days after surgery and in the intact metaphysis of the contralateral limb (\%)

\begin{tabular}{l|c|c|c}
\hline \multicolumn{1}{c|}{ Elements } & Cont & Exp & $\begin{array}{c}\text { Metaphysis of } \\
\text { contralateral limb }\end{array}$ \\
\hline Sodium & $0.41 \pm 0.02$ & $0.44 \pm 0.02$ & $0.40 \pm 0.02$ \\
Magnesium & $0.22 \pm 0.01$ & $0.25 \pm 0.01$ & $0.22 \pm 0.01$ \\
Phosphorus & $1.93 \pm 0.04$ & $2.94 \pm 0.13^{1}$ & $3.22 \pm 0.15$ \\
Sulfur & $0.23 \pm 0.01$ & $0.30 \pm 0.02^{2}$ & $0.22 \pm 0.01$ \\
Calcium & $3.85 \pm 0.16$ & $5.89 \pm 0.26^{1}$ & $6.44 \pm 0.31$ \\
\hline
\end{tabular}

Note: ${ }^{1,2}$ Statistical significance of intergroup differences: ${ }^{1} P<0.001,{ }^{2} P<0.05$

\section{Discussion}

Substitution or reconstruction of extensive bone cavity defects caused by congenital or acquired pathology is an actual medical and social problem. The main methods of surgical treatment are variants of bone grafting with the use of various synthetic, biological and composite materials. However, when studying the long-term results, it was found that most of these materials are not osseointegrated, but are surrounded by a fibrous capsule. The use of one's own bone (autotransplantation) is associated with an additional traumatic effect and is limited by the inability to take the necessary amount of autologous bone material, especially in children. In this case, there is also a risk of transmission of various diseases and the development of a number of serious complications of the immune nature, which are often accompanied by graft rejection and suppuration in the postoperative period. ${ }^{(14)}$

The results of this study showed that the implant we studied performed well the defect form, had good biocompatibility, and expressed osteoconductive properties. The microporous structure of the surface layer of the implant filaments ensured the adhesion of the cells of the regenerate and the formation of the osseointegrative compound, which was maintained until the end of the experiment. The development of osteogenic differentiation of cells on the surface of the implant was proved by the development of a specific calcified matrix. Regenerate tissues and blood vessels easily germinated into the implant without disrupting its integrity. In the periosteal region of the defect, a layer of dense connective tissue was formed on the surface of the implant, which served as a biological protective barrier preventing the germination of paraosal connective tissue. The defect was compensated by a spongy bone, the bulk density 
of which at all stages of the experiment was more than one and a half times higher than the control indices, and its mineral composition approximated the parameters of the spongy bone of the intact metaphysis. Reparative bone formation was carried out by a type of direct intramembranous osteogenesis. In none of the cases were there signs of an inflammatory process, which confirmed the data we had received earlier. ${ }^{(15)}$ For the first time during the implantation, an artificial composite biological tissue reinforced with $\mathrm{TN}$ filaments was obtained: dense fibrous connective tissue, spongy and compact bone. The fine-celled structure and micro porosity of the surface of the implanted structures created capillary properties, due to which endogenous bone morphogenetic proteins and growth factors were adsorbed. The functional activity of the latter - providing proliferation and accelerated differentiation of osteogenic cells; stimulating the synthesis of collagen, osteocalcin, and alkaline phosphatase; and activating the mineralization of the organic matrix of bone - ensured the osteoinductiveness of the implant.

\section{Conclusion}

The implant made of mesh structures of titanium nickelide is an effective osteoconductor and osteoinductor, and provides prolonged activation of reparative bone formation and spatial development of bone tissue in the defect. Atraumatism of surgical intervention and the absence of biological rejection reaction places the implant in the range of the most optimal osteoplastic materials, and its application seems theoretically grounded and promising, especially in patients with reduced osteogenetic and reparative potential, including in mature and elderly patients, as well as in children.

\section{Conflict of interest}

The authors declare that they have no competing interests.

\section{References}

1. Liu J, Kerns DG. Mechanisms of guided bone regeneration: a review. Open Dent J. 2014;8:56-65. doi: 10.2174/1874210601408010056.

2. Jung RE, Fenner N, Hämmerle CH, Zitzmann NU. Longterm outcome of implants placed with guided bone regeneration
(GBR) using resorbable and non-resorbable membranes after 12-14 years. Clin Oral Implants Res. 2013;24(10): 1065-73. doi: $10.1111 /$ j.1600-0501.2012.02522.x.

3. Hämmerle CH, Jung RE. Bone augmentation by means of barrier membranes. Periodontol. 2003;33:36-53.

4. Karring T, Nyman S, Gottlow J, Laurell L. Development of the biological concept of guided tissue regeneration--animal and human studies. Periodontol. 2000;1:26-35.

5. Schmidmaier G, Baehr K, Mohr S, Kretschmar M, Beck S, Wildemann B. Biodegradable polylactide membranes for bone defect coverage: biocompatibility testing, radiological and histological evaluation in a sheep model. Clin Oral Implants Res. 2006;17(4):439-44.

6. van Leeuwen AC, Huddleston Slater JJ, Gielkens PF, de Jong JR, Grijpma DW, Bos RR. Guided bone regeneration in rat mandibular defects using resorbable poly(trimethylene carbonate) barrier membranes. Acta Biomater. 2012;8(4):14229. doi: 10.1016/j.actbio.2011.12.004.

7. Dahlin C, Linde A, Gottlow J, Nyman S. Healing of bone defects by guided tissue regeneration. Plast Reconstr Surg. 1988;81(5):672-6.

8. Urist MR, McLean FC. Recent advances in physiology of bone. I. J Bone Joint Surg Am. 2003;45:1305-13.

9. Dahlin C, Sennerby L, Lekholm U, Linde A, Nyman S. Generation of new bone around titanium implants using a membrane technique: an experimental study in rabbits. Int $\mathbf{J}$ Oral Maxillofac Implants. 1989;4(1):19-25.

10. Schropp L, Wenzel A, Kostopoulos L, Karring T. Bone healing and soft tissue contour changes following single-tooth extraction: a clinical and radiographic 12-month prospective study. Int J Periodontics Restorative Dent. 2003;23(4):313-23. 11. Iasella JM, Greenwell H, Miller RL, Hill M, Drisko C, Bohra AA, Scheetz JP. Ridge preservation with freezedried bone allograft and a collagen membrane compared to extraction alone for implant site development: a clinical and histologic study in humans. J Periodontol. 2003;74(7):990-9.

12. Iriyanov YM, Chernov VF, Radchenko SA, Chernov AV. Plastic efficiency of different implants used for repair of soft and bone tissue defects. Bull Exp Biol Med. 2013;155(4):518-21.

13. Iryanov YuM, Iryanova TYu. The implant to replace bone defect. RF Patent 111759. Bul 36;2011:1 [in Russian].

14. Uebersax L, Hagenmüller H, Hofmann S, Gruenblatt E, Müller R, Vunjak-Novakovic G, et al. Effect of scaffold design on bone morphology in vitro. Tissue Eng. 2006;12(12):3417-29. 15. Osyczka AM, Diefenderfer DL, Bhargave G, Leboy PS. Different effects of BMP-2 on marrow stromal cells from human and rat bone. Cells Tissues Organs. 2004;176(1-3):109-19. 